\title{
Failure of spreading depression to produce retrograde amnesia'
}

\author{
IRVING KUPFERMANN ${ }^{2}$ \\ UNIVERSITY OF CHICAGO
}

\begin{abstract}
Abstraet
Bilateral spreading depression, produced in rats immediately after they learned a pattern discrimination (horizontal vs. vertical stripes, food reinforcement), did not lead to retention deficits the following day. Problem

The role of the cerebral cortex in the consolidation process can be studied by means of cortical spreading depression (SD), since spreading depression disrupts cortical neural activity, without markedly disturbing the rest of the brain. A few studies, using shock-reinforcement, have indicated that spreading depression produced immediately after a learning session leads to a retention deficit the next day (Bureš \& Burešová, 1963; Pearlman \& Jarvik, 1961). The present study attempted to determine the effects of spreading depression following training with food reinforcement.
\end{abstract}

\section{Method}

Eleven male Sprague-Dawley rats were trained in a modified Munn discrimination box to make a discrimination between horizontal and vertical stripes $(1 \mathrm{~cm}$ stripes, vertical positive). Reward consisted of wet mash, and a correction procedure was used. Details of the stimuli, training, and pretraining methods have been presented elsewhere (Kupfermann, 1965).

In a single session, Ss were trained to a criteria of six consecutive correct responses. In six Ss immediately after reaching criterion, bilateral SD was produced through trephine holes over the visual cortex, using the method described by Bureš \& Burešová (1963). The presence of SD was determined by noting bilateral failure of tactual and visual placing. The whole procedure, from the start of training until the induction of the SD, never took more than $20 \mathrm{~min}$.

Twenty-four hours after training, retention was tested by retraining to a criterion of nine out of ten correct responses.

\section{Results}

Table 1 shows the number of errors to learn the original discrimination and relearn it the following day. The scores of the experimental and control groups are almost identical. It should be noted that three of the experimental animals showed perfect retention.

\section{Discussion}

Since cortical SD markedly disturbs all cortical neural activity (Morlock et al, 1964), failure of it to affect the retention of the present task suggests that the cortex is not critically involved in the consolidation process for this task. Another possibility is that disruption of the consolidation process shown in previous studies did not result from simple interference with ongoing neural activity. The retrograde amnesia produced by electroconvulsive shock and drugs may result from excessive neural stimulation, or from direct interference with the biochemical processes underlying consolidation.

There are several possibilities of why previous studies found retrograde amnesia following SD, while the present study did not. The most likely explanations are the following:

1. The SD in previous experiments may have been stronger and longer lasting than the SD in this experiment. Longer lasting SD may be more effective, either because it is more likely to spread subcortically, or because it may cause changes beyond simple interference with on-going neural activity.

2. The previous studies used negative reinforcement during training, while the present study used positive reinforcement. Tasks involving negative reinforcement may be more susceptible to cortical SD, or to SD that spreads subcortically. Cortical SD in rats may very likely pass into the amygdala and nearby structures (Fifková \& Syka, 1964); and Goodard (1964) feels that the amygdala is involved only in the consolidation of the association of a stimulus with a noxious event, and not with a positively reinforcing event.

Table 1. Number of Errors to Reach Criterion on Original Learning and Relearning for Control Animals and Animals Subjected to Spreading Depression after Reaching Original Criterion

Subjects Original Learning Relearning

Control Group

$\begin{array}{lll}88 & 13 & 00 \\ 89 & 21 & 00 \\ 90 & 18 & 00 \\ 92 & 22 & 02 \\ 93 & 07 & 07 \\ \text { Mean } & 16.2 & 1.80\end{array}$

Spreading Depression Group

$\begin{array}{lll}86 & 09 & 00 \\ 94 & 17 & 00 \\ 95 & 33 & 01 \\ 96 & 16 & 00 \\ 97 & 12 & 07 \\ 98 & 05 & 05 \\ \text { Mean } & 15.5 & 2.17\end{array}$


3. The tasks in the previous studies may be more sensitive to a partial amnesia caused by spreading depression.

\section{References}

Bureš, J., \& Burešová, o. Cortical spreading depression as a memory disturbing factor. J. comp. physiol. Psychol., 1963, 56, 268-272.

Fifková, E., \& Syka, J. Relationships between cortical and striatal spreading depression in rat. Exp. Neurol., 1964, 9, 355-366.

Goodard, G. V. Amygdaloid stimulation and learning in the rat. J. comp. physiol. Psychol., 1964, 58, 23-30.

Kupfermann, I. The role of cortical steady potentials in visual discrimination. Exp. Neurol., 1965, in press.

Morlock, N. L., Mori, K., \& Ward, A. A., Jr. A study of single cortical neurons during spreading depression. J. Neurophysiol., 1964, 27, 1192-1198.

Pearlman, C., \& Jarvik, M. E. Retrograde amnesia produced by spreading cortical depression. Fed. Proc., 1961, 20, 340.

\section{Notes}

1. This paper is based upon part of a dissertation submitted to the Psychology Department at the University of Chicago in partial fulfillment for the requirements for the Ph.D. degree. The work was supported (in part) by a predoctoral Research Fellowship (No. MF-12,240) from the United States Public Health Service, and by NIH Grant No. NB-03816-3 to Dr. K. L. Chow. Preparation of the manuscript was supported (in part) by NIH Grant No. MH-5755-4 to Dr. R. A. McCleary.

2. Present address, Laboratory of Neurophysiology, Massachusetts Mental Health Center.

\section{Abstraet}

CORSON, J。A.(McGill U。). Memory as influenced by a single electroconvulsive shock. J.psychiat. Res.。 in press-This study was an investigation of the role of task difficulty and variations in previous ex- perience as variables which might influence the susceptibility of particular memories or habits a d sup " ny electroconvulsive shock. Three experiments We, e wone in which a total of 86 rats learned spatial or visual discriminations with shock motivation. Electroconvulsive shock was administered $30 \mathrm{sec}$. after criterion was reached. Large differences were found in the susceptibility of different habits to disruption by electroconvulsive shock, and large differences were found in the susceptibility of the same habit when it was preceded by different forms of pretraining. The eventual effect of electroconvulsive shock on certain habits was changed by experience which took place 24 , or more, hours before the habits in question were learned. These results are interpreted as pointing out limitations of existing hypotheses concerning the effects of electroconvulsive shock. (Pre-publication copies available from the author.)

\section{Editorial Note}

Readers will note some changes in the type styles used for setting cover material, some headings, and references and notes. These changes are made possible by additional composing equipment now in place in the editorial office. They are intended to improve the appearance of the journal and at the same time reduce somewhat the costs of composing special materials. Other minor changes will be made at a later date when additional items on order have been received. 